ORIGINAL ARTICLE

\title{
Constructions of self: ethical overtones in surprising locations
}

\section{E A Kinsella}

J Med Ethics; Medical Humanities 2005;31:67-71. doi: 10.1136/jmh.2005.000201

Little discussion has occurred in the health profession literature with respect to how the "self" is constructed, despite the imagination and attention it has garnered from philosophers and theorists in various other disciplines. Yet this subject has surprisingly ethical overtones for health professional education and practice. In this paper notions of the self are briefly considered and it is suggested that a narrative and dialogic view of self can contribute to insights about ethical practice in the health professions. Subtle issues with respect to how relationship and language may be used to wield power are revealed and discussed; and awareness about how such power is used in practice is highlighted as a crucial issue. The assumptions practitioners make with respect to constructions of self are ethically important and this topic warrants consideration in the medical humanities.

Correspondence to: Elizabeth Anne Kinsella, PhD, MAdEd, BSc, Assistant Professor, Faculty of Health Sciences, University of Western Ontario, 1201 Western Road, Elborn College, London, Ontario, Canada, N6G 1H1; akinsell@wo.ca

Received

6 September 2004 Accepted for publication 16 February 2005
W hile conceptions of "self" may seem self explanatory and often appear to be taken as self evident within health professions, the literature concerning how the self is constructed has been burgeoning in other fields. Various philosophers and theorists have, in recent years, drawn attention to conflicting conceptions of the self, and raised this as an important domain of concern at both a theoretical and practical level. Conceptions of the "self" vary, from interpretations that focus on 1) the unitary rationalistic subject of the enlightenment project, to 2) decentred and fragmented poststructural and postmodern subjects, to 3) narrative and dialogic views. These three perspectives are considered in the first section, followed by discussions that highlight ethical issues revealed when one attends to a narrative and dialogic conception of the self.

I argue that health practitioners possess significant power to either affirm or demean the individual's conceptions of self, and harm can occur when practitioners fail to recognise this power. Further, subtle ethical issues with respect to how relationship and language may be employed to wield power in healthcare practice are considered. The question of how this power can be ethically used in healthcare practice is raised.

This article adopts a hermeneutic approach. ${ }^{1-3}$ Ferraris $^{4}$ views hermeneutics as "the art of interpretation as transformation" and contrasts it with a view of theory as "contemplation of eternal essences unalterable by the observer". A hermeneutic approach seeks understanding rather than explanation, acknowledges the situated location of interpretation, recognises that language and history are both conditions and limitations of understanding, views inquiry as conversation, and is comfortable with ambiguity. ${ }^{13}$ For Gadamer" hermeneutics "is entrusted with all that is unfamiliar and strikes us as significant". From this perspective, the meaning of a text is not to be compared with an immovably and obstinately fixed point of view, rather "to understand a text means always to apply it to ourselves and to know that, even if it must always be understood in different ways it is still the same text presenting itself to us in these different ways" (Gadamer, ${ }^{2}$ pp 388, 389). A hermeneutic approach is open to the ambiguous nature of textual analysis and invites a polyphony of perspectives into the conversationtherefore perspectives that may not otherwise come into dialogue with one another and that cross traditional borders are brought together in conversation. A hermeneutic attitude is revealed in this study through a posture of conversation, as invitation to reflect on the tensions that arise in the discussion.

\section{CONSTRUCTIONS OF "SELF": THREE PERSPECTIVES \\ Unitary self}

The unitary self of the enlightenment project has been depicted as presupposing an essence at the heart of the individual, which is unique, fixed, and coherent and which makes her or him what she or he is. ${ }^{6}$ This individuated rational selffrequently attributed to Descartes and his famous dictum "I think therefore I am"perceives itself through self reflection. Cognition, from this perspective, appears as a type of inner contemplation, conducted by the solitary meditator. ${ }^{7}$ Such a conception presupposes a self who experiences the world independently of the language and discourse in which statements about the world are made. ${ }^{8}$ Also, the focus on the individual is distinct from older dialogic views of existence. ${ }^{7}$ This unitary, rational self, a knowing subject who comes to know itself through self reflection, is the conception that implicitly informs much humanist discourse.

\section{Fragmented and decentred self}

In contrast, postmodern and poststructuralist views posit a conception of a fragmented, decentred self. Postmodern writers question whether the self is unified, singular, and self determining, highlighting, as Lyotard' does, that 
each self exists in a fabric of relations. Poststructuralism proposes a self that is precarious, contradictory, and in process, constantly being reconstituted in discourse each time we think or speak. ${ }^{6}$ Foucault—for example, ${ }^{10}$ argues that as subjects there is no single position from which we can be empowered but only particular discursive positions within power/knowledge formations. For Foucault, subjects are constituted in discourse.

In Lacan's view, individuals are constituted as divided subjects, ${ }^{11}{ }^{12}$ split between the subject of being (the self identified as "me") and the subject of language (the self identified as "I") (Carson, ${ }^{12}$ p 80). The "subject of being" located in the imaginary order cannot be conflated with the "subject of speech" located in the symbolic order. As Lacan points out: "I identify myself in language, but only by losing myself in it like an object" (Carson, ${ }^{12}$ p 80). Lacan draws attention to the separation between the subject in "being" and the subject in "speech" and seeks to differentiate rather than conflate the two (Carson, ${ }^{12}$ p 80). Without this distinction, it is assumed that we are able to stand over against ourselves, and our practices, as if we are knowing subjects standing in relation to an object; yet postmodern and poststructural theories call this assumption into question (Carson, ${ }^{12}$ p 80).

From a postmodern/poststructuralist point of view, curricula in healthcare education that fail to problematise the modern notion of an individuated, self transparent consciousness, fully in control of itself, are problematic. Postmodern and poststructuralist thinkers contend that the self is more than cognitive and rational minds ruling bodies; the self is also constituted and reconstituted in relationship and language. This is a conversation that I suggest requires considerably more attention than it has received to date in healthcare professions. Postmodern and poststructural perspectives invite those working in health education to become reflexive about the conceptions of self that subtly pervade professional preparatory programmes.

\section{Narrative and dialogic self}

An alternative view of the self, which is responsive to issues of relationship and language yet maintains the agency of the individual, is a narrative and dialogic one. Such a conception offers promise for healthcare education and illuminates ethical imperatives that may otherwise remain invisible.

Numerous theorists have suggested that narrative is a fundamental way of attributing meaning in our lives, ${ }^{13}{ }^{14}$ and that constructing stories about the self is linked to the construction of self identity. ${ }^{13} 15^{16}$ Lindemann Nelson $^{15}$ captures this idea eloquently:

Personal identities consist of a connective tissue of narratives-some constant, others shifting over timewhich we weave around the features of our selves and our lives that matter most to us. The significant things I've done and experienced, my more important characteristics, the roles and relationships I care about most, the values that matter most to me-these form the relatively stable points around which I construct the narratives that constitute the sense I make of myself. The stories of my connection to these things over time are explanatory: they explain to me who I am and it's this that is my own contribution to my personal identity.

Similarly, Polkinghorne ${ }^{16}$ highlights the narrative achievement of personal identity as follows:

We achieve our personal identities and self concept through the use of the narrative configuration, and make our existence into a whole by understanding it as an expression of a single unfolding and developing story. We are in the middle of our stories and cannot be sure how they will end; we are constantly having to revise the plot as new events are added to our lives. Self, then, is not a static thing or a substance, but a configuring of personal events into an historical unity which includes not only what one has been but also anticipations of what one will be.

As well as acknowledging the individual's role in constructing his or her self concept through narrative configuration and revision, European philosopher Richard Kearney ${ }^{17}$ calls for attention to a dialogic dimension. Such an account recognises that a narrative configuration of the self involves not only a reflexive relationship of self to self, but also a relationship of self to other. ${ }^{18}$ This relationship of self to other may be referred to as intersubjectivity-a relation and response between the subjectivity of the self and the subjectivity of the other. This interanimation or intersubjectivity is achieved through dialogue, and draws on the vehicle of language.

The word dialogue comes from the Greek word dialogos. ${ }^{19}$ "Logos means 'the word', or...the 'meaning of the word'. And dia means 'through'...The picture or image that this derivation suggests is of a stream of meaning flowing among and through us and between us" (Bohm, ${ }^{19}$ p 6). In physicist/ philosopher David Bohm's view, ${ }^{19}$ dialogue is a process of direct face to face encounter that insists on facing the inconvenient messiness of daily, corporeal lived experience. This dialogic dimension is an invitation to test the viability of traditional definitions of what it means to be human, and collectively to explore the prospect of an enhanced humanity. ${ }^{20}$

Similarly, philosopher Charles Taylor ${ }^{21}$ argues that the general feature of human life is its fundamentally dialogical character, and that identities are formed in open dialogue. For Taylor the formation of identity crucially depends on one's dialogical relations with others. He writes: "My discovering my identity doesn't mean that I work it out in isolation but that I negotiate it through dialogue, partly overtly, partly internalised, with others" (Taylor, ${ }^{21}$ pp 47-8). Taylor suggests that we become full human agents, capable of understanding ourselves, and hence of defining an identity, through our acquisition of rich human languages of expression. These include not only words but languages of art, gesture, love, and the like. Yet, we do not acquire the languages needed for self definition on our own, rather we are introduced to them through exchanges with others who matter to us. The genesis of the human mind is in this sense not "monological", not something each accomplishes on his or her own, but dialogical (Taylor, ${ }^{21}$ p 33). Taylor notes that dialogue invokes both agreement and struggle, as "our identities are formed in dialogue with others, in agreement or struggle with their recognition of us" (Taylor, ${ }^{21}$ pp 45-6). Dialogical relationships carry weight in our constructions of self as "we are all aware how identity can be formed or malformed in our contact with significant others" (Taylor, ${ }^{21}$ pp 49-50).

The dialogic nature of human life is highlighted as an important complement to traditional conceptions of narrative. The achievement of identity is viewed as both an individual and an intersubjective event. Such a recognition raises ethical issues for practitioners in health care, which are elaborated in subsequent sections of this paper.

The work of European philosopher Richard Kearney and Russian philosopher Mikhail Bakhtin also support a narrative and dialogic conception of the self. Philosopher Richard Kearney $^{17}$ notes that a narrative and dialogic perspective retains the agency of the practitioner while taking 
intersubjectivity and language into account. He argues that following postmodernism and poststructuralism, theorists must reinvent a genuine narrative subject. He proposes a narrative self prepared to work through the pain of the past in dialogue with its Others. Kearney calls for "a postdeconstructionist subject, able to carry out acts of semantic innovation (poetics) and just judgment (ethics)" (Kearney, ${ }^{17} \mathrm{p}$ 188). He believes it is possible to take on the postmodern assaults on the unitary subject without dispensing with all notions of selfhood. Kearney argues that "without some sense of self there can be no sense of the other-than-self," yet paradoxically "the shortest route from self to self is always through the other" (Kearney, ${ }^{17} \mathrm{p} \mathrm{189}$ ). In contrast to the Cartesian perspective, he argues that meaning "does not originate within the narrow chambers of its own subjectivity, but emerges as a response to the other, as radical intersubjectivity".22

Bakhtin's thinking also supports a reinvigoration of a narrative and dialogic conception of the self. ${ }^{23}$ Bakhtin contends that we exist through "the borrowed axiological light of otherness", ${ }^{24}$ highlighting the intersubjective and dialogic nature of existence. Bakhtin proposes acting agents whose ethical actions are constituted, in particular, unique acts. Bakhtin believes that our lives can be consciously comprehended only in answerability. By answerability he refers to our ability to take responsibility for our acts (including thoughts). In Toward a Philosophy of the Act, Bakhtin writes: "My entire life as a whole can be considered as a single complex act or deed that I perform". ${ }^{25}$ An answerable life, according to Bakhtin, is one in which there is "no alibi" for Being. He says that "A life that has fallen away from answerability cannot have a philosophy: it is by its very principle, fortuitous and incapable of being rooted" (Bakhtin, ${ }^{25}$ p 56). Answerability invokes "the necessity of dialogue between two people who come into an event with specific horizons of meaning, and who then act to answer others' actions". ${ }^{26}$ Bakhtin's "answerable" subject, then, reflects a narrative and dialogic self. In this view the individual is answerable to another, meaning is creatively reconstituted and shifted through dialogue, yet the individual maintains a sense of agency. The self in this conception is not reduced to a pawn constructed solely by external forces, yet neither is the individual a solitary, self contained being. Thus, Bakhtin's views depict an evolution from the "unitary" self and the "fragmented" self to support a conception of a narrative and dialogic self.

In summary, a narrative and dialogic notion of self engages with the spaces between the conceptions of a modern unitary essential and individuated self (known through self reflection) and a postmodern decentred and fragmented self (constituted in discourse and social relations). Such a perspective recognises the achievement of personal identities and self concept through the use of the narrative configuration, viewing the self not as a static thing or a substance, but rather as an active agent who configures personal events into a historical unity; while also recognising the dialogic nature of identity and therefore the central role of intersubjectivity (response to/from the other) and language (the vehicle for such response) in its configuration.

In light of a narrative and dialogic conception of self, ethical considerations arise, which I consider in the following two sections. In the first section, I suggest that harm can occur in practice when healthcare practitioners fail to recognise the power they wield with respect to relational and intersubjective considerations that influence identity. I argue that health practitioners possess significant power to either affirm or demean the identity of the other. In the second section, I seek to reveal ethical issues with respect to how language and discourse may be employed in healthcare practice, and to highlight ethical imperatives for a thoughtful consideration of how this power is used in practice.

\section{ETHICAL RELATIONSHIP AND INTERSUBJECTIVITY}

What occurs in practice when we fail to consider the intersubjective or dialogic nature of experience in our theoretical constructs? With respect to client relationships, Taylor and White ${ }^{27}$ note that while practitioner reflection opens up the possibility of a more uncertain, ambiguous, and complex world, it has the potential to close much of this down again. By freezing practitioners' accounts, as true representations of what happened, practitioner reflection can unintentionally obscure client perspectives. Such a privileging of the practitioner perspective can be dangerous.

In healthcare practice, the practitioner's experience and constructions become very powerful, and given that the professional is often already in a position of power with respect to his or her client, the professional's constructions may occlude the experience of the "Other" and may even disempower clients. This certainly does not call for an exclusion of attention to practitioner reflection, which is certainly a step in a progressive direction. Rather, I suggest that it calls for greater attention to the intersubjective and dialogic nature of experience in practice. This includes attention to and discussion about the ways in which clients construct meanings, and the creation of environments that foster dialogic communication. I suggest that a humble recognition is required that individuals are "cocreators" of meaning within practice environments-even and most particularly when one party is privileged with the social status of "expert". Once again, philosophers Charles Taylor, Richard Kearney, Mikhail Bakhtin, and others offer perspectives that contribute to this conversation.

Taylor $^{21}$ suggests that an original identity needs (and is vulnerable to) the recognition given or withheld by significant others. According to Taylor, equal recognition is not just the appropriate mode for a healthy democratic society: its refusal can inflict damage on those who are denied it. The projecting of an inferior or demeaning image on another can actually distort and oppress, to the extent that it is interiorised. People's beliefs bear directly on the construction and misconstruction of personal identities, and it is that aspect of oppression that is of concern. ${ }^{15}$ Practitioners have considerable power to grant or withhold recognition of significant others and to grant or withhold spaces in which divergent accounts of meaning and identity can be expressed and tested. Acknowledgement of this power and consideration of its ethical use within professional relationships is crucially important.

Kearney $^{22}$ draws on continental philosopher Emmanuel Levinas $^{28}$ to demonstrate that, in ethical relationship, the face of the other calls out to us for response before epistemological and ontological concerns. Levinas calls this the ethical relation of the "face to face". Another in need makes the ethical demand on me: where are you? We are responsible for the suffering of the other in that face to face moment Kearney, ${ }^{22}$ p 362). With respect to healthcare practice, to simply reflect on one's own interpretations without a consideration of the "face of the other" and an acknowledgement of the "Other's" construction of meaning, in light of one's own, raises ethical questions. As mentioned earlier, Kearney believes that meaning emerges as a response to the other, as radical intersubjectivity.

Bakhtin's thoughts on ethical relationship also provide a useful way to think about intersubjectivity. Bakhtin suggests that in ethical relationship we as individuals are answerable to another through our non-alibi in Being. ${ }^{25}$ He writes: "To live from within oneself does not mean to live for oneself, but means to be an answerable participant from within oneself, 
to affirm one's compellent, actual non-alibi in Being" (Bakhtin $^{25}$ p 49). Bakhtin points out that without an adequate consideration of human encounters, we are in danger of confronting "the other as a thing, as a raw material to be objectified and manipulated in accordance with an egocentric self interest" ${ }^{\prime 2}{ }^{29}$ This is opposed to his view of the other "as a unique and singular being, in which a dialogical relation is reciprocal and mutually enriching" ${ }^{29}$ According to Bakhtin $^{30}$ monologic approaches that centre only on the individual's construction of meaning deny the dialogic nature of existence, refuse to recognise the responsibility of the addressee, and pretend to be the "last word". Bakhtin believes that meaning is always a becoming, the result of the dialogic give and take between the inside and the outside, the self and the world, the self and the other. In his view, meaning is intertextual and dialogic.

The preceding discussion raises many issues. As opposed to separate individuated human beings, as in the unitary conception of self, the self is portrayed as vulnerable to, but also informed and potentially liberated by, others. In this way, the role of intersubjectivity in the constitution of identity is highlighted. One potential implication of "constructions of self" that exclude a focus on intersubjectivity is the danger of creating environments that unintentionally demean or oppress, that treat clients or coworkers as objects of our reflections-that is, as things.

If meaning is indeed intersubjective and dialogically constituted, the practitioner is called to be answerable to the "other". This can be a challenge, particularly in healthcare environments that promote practitioners as experts, and that emphasise "evidence" and "efficiency". To be answerable to another demands that one must not be fearful of showing one's weakness; it demands humility and openness as opposed to pride and arrogance. Such a view runs contrary to many hierarchical and expert centred environments. For instance, if one shows humility and openness it can be perceived as self doubt, as lack of confidence, as "not knowing". I suggest that this is an important area of consideration in professional environments, and particularly in health profession environments. How can we promote cultures that invite openness, dialogue, and responsiveness as opposed to monologic or arrogant approaches to health care?

A central question raised for me is whether health professional education goes far enough in the promotion of ethical dialogical relationships that acknowledge intersubjective dimensions in professional practice, and whether the call to "professionalism" carries with it the danger of treating service users and colleagues as simply objects of practitioner reflections and constructions.

I suggest that more attention to intersubjective elements, with respect to conceptions of how the self is constructed, is warranted in health professional education.

\section{ETHICAL ISSUES IN LANGUAGE AND DISCOURSE}

Ethical issues relative to language and discourse are revealed when a narrative and dialogic view of the self is considered. Rich $^{31}$ highlights the power of language, noting that it is the vehicle through which people name, describe, and depict, and that through its corruption, language can also be used to manage our perceptions. Indeed, language has the power to organise our thought and experience and to frame the issues to which we address our attention. ${ }^{32}$ Language then has a constitutive moral relation to its objects. ${ }^{33}$ When such an understanding of language is applied to practice, the question of who frames the issues and whose version of reality holds sway is raised. Indeed, the potential to silence certain versions of reality through language is reflected in Cixous's insight that "all narratives tell one story in place of another story". ${ }^{34}$

In contrast to a non-problematic realist view of language, Foucault $^{35}$ is concerned with discourse as a system of representation. His main concern is with a broad macrolevel analysis of discursive systems, and the relations of such systems to issues of power, as opposed to microlevel language analysis. ${ }^{36}$ In Foucault's ${ }^{35}$ view, discourse "creates a field of knowledge by defining what is possible to say and think, declaring the bases for deciding what is true and authorising certain people to speak while making others silent or less authoritative" (Foucault, ${ }^{35}$ p 49). Gee ${ }^{37} 38$ points out that discourses can be seen as ideological because they involve a set of values and viewpoints in terms of which one must speak and act, at least while one is in the discourse; otherwise one does not count as being in it.

Professional discourses (fields of knowledge) operate within particular professions, within disciplines, and within various institutions. Although often unacknowledged, professional discourses influence the manner in which practitioners act. Discursive regimes are linked to power, in that "expert" practitioners can claim cognitive authority over the stories of practice. "Cognitive authority" is a term coined by feminist philosopher Kathryn Pyne Addelson. ${ }^{39}$ It refers to the authority to have one's descriptions of the world taken seriously, believed, or accepted generally as truth. In professional practice, the discourses of professionals are frequently granted cognitive authority over the reports of others, and those of more powerful disciplines are often granted greater cognitive authority than those of less powerful groups. Rich ${ }^{40}$ highlights the capacity of those with cognitive authority to silence other stories and points out the consequent potential for what she calls psychic disequilibrium. She writes: "When someone with the authority of a teacher, say, describes the world and you are not in it, there is a moment of psychic disequilibrium, as if you looked into a mirror and saw nothing" (Rich, ${ }^{40} \mathrm{p}$ ix).

Frye $^{41}$ describes a dominant position: one that excludes the other, takes one's own standpoint as central, one's own needs, opinions, desires, and projects as the salient ones, and one's experience and understanding as what is the case (Nelson, ${ }^{15}$ p 9). Frye points out that oppressive master discourses commonly construct the identities of others from the perspective of the arrogant eye, dismissing or degrading what does not bear directly on their value to the dominant group. A failure to become conscious of the tendency to assimilate such "authoritative discourses" into one's or one's client's identity is a danger in professional practice.

Whereas control over discourse is a vital source of power, it is important to note that there are limits to this control because meanings are fluid and can be reworked to resist domination. ${ }^{42} 43$ Thus, both practitioners and clients have the capacity to actively resist or struggle with the meanings ensconced in authoritative discourses. Frye ${ }^{41}$ has recognised that not all practitioners adopt the arrogant gaze highlighted above. Frye counters the "arrogant eye" with a "loving eye", one that confers the cognitive authority withheld by the arrogant gaze, such that discursive accounts that fall outside of the master discourse are not delegitimated (Nelson, ${ }^{15}$ p 9).

As an example, feminist philosopher Susan Wendell ${ }^{44}$ relays the story of Gloria Murphy, a woman who experienced acute dizziness, numbness in the legs, inability to walk at times, double vision, bladder, kidney, and bowel trouble. During most of the five years between the onset of her symptoms and her diagnosis of multiple sclerosis she was told by the Mayo clinic and others, that she had "housewife's syndrome" and needed to get busy and away from the children to feel better. The cognitive authority of this master discourse caused her to engage in extensive volunteer work 
and activities, despite frequent rehospitalisations, and to doubt her own strong feeling that something was very wrong. When she was diagnosed she was elated, the response was the result of being rid of a terrible conflict, between what Gloria felt and what the master discourse demanded that she believe about herself. Perhaps a "loving gaze" could have helped Gloria to acknowledge and affirm the authority of her experience.

Once again ethically important issues arise. In the health professions, explicitly acknowledging the nature of discursive systems and reflecting upon the implications of powerful discourses with respect to the construction of identity becomes important. Another important issue is the imperative to critique dominant discourses and to recognise their power to legitimate who is permitted to name the values or problems of practice and who is granted cognitive authority. This question of whose version of the world is told, and whose is silenced, is an important one. The potential of discursive systems to contribute to the constructions of identity, to suppress certain accounts, and to infuse others with authority reveals an important ethical dimension of practice that is not often considered in health professional education yet which influences the manner in which practitioners behave.

\section{CONCLUSION}

\section{Constructions of self and ethical practice}

How one wields relational and discursive power is an ethical matter. Therefore, conceptions of the self that consider intersubjectivity and language have profound implications for ethical practice. Chapman ${ }^{43}$ advocates not a universalising and objectifying moral code but a constantly evolving ethical practice grounded in the everyday, in which the practitioner is conscious of and attempts to wield power in an ethical manner. Such an ethical practice is informed by the "loving eye" posited by Frye $e^{41}$ - a gaze that recognises the cognitive authority of discourses beyond its own. I suggest that attention to the problematic nature of intersubjectivity, discourse, and language in professional practice are important sites for ethical discussions in healthcare fields.

Conceptions of how the "self" is "constructed"-while seemingly abstract and theoretical-are, I contend, immensely practical. Such conceptions inform the ethical considerations that carry weight in our day to day interactions and behaviours in practice. The manner in which health practitioners use or misuse relationships and language to construct "Others", to construct versions of reality, to construct meaning, and to wield cognitive authority has immense implications for day to day life in healthcare environments. I suggest that a narrative and dialogic conceptualisation of the "self" allows for a dialogue about these issues, and holds much promise for the education and practice of health professionals of the future. Yet I recognise that fostering such a view is not without challenges; given that modernist notions appear to underpin current practices, decisions about conceptions of self are not widely recognised as ethically significant, and tensions are created in environments that promote practitioners as experts.

Nonetheless, the elaboration of a narrative and dialogic conception of the self, and the study of intersubjectivity and language use as they relate to power, offer promising locations for further study, as well as profound sites for the consideration of ethical imperatives for practice in the health professions.

\section{ACKNOWLEDGEMENT}

This work was supported in part by The Social Sciences and Humanities Research Council of Canada. The author wishes to thank Sharon Rich, Michael Gardiner, Dorothy Landers, Sandy Deluca, Fred
Ellett, John Reigle and Allan Pitman for critical conversations about ideas presented in this paper.

\section{REFERENCES}

1 Gadamer HG. Philosophical hermeneutics [trans Linge D]. Berkeley: University of California Press, 1976.

2 Gadamer HG. Truth and method [trans Weinsheimer J, Marshall D]. New York: Continuum, 1996.

3 Jardine D. Reflections on education, hermeneutics, and ambiguity: hermeneutics as a restoring of life to its original difficulty. In: Pinar W, Reynolds W, eds. Understanding curriculum as phenomenological and deconstructed text. New York: Teachers College Press, 1992:116-30.

4 Ferraris M. History of hermeneutics [trans Somigli L]. Atlantic Highlands, NY: Humanities Press, 1996:1.

5 Gadamer HG. Interview: writing and the living voice. In: Misgeld D, Nicholson G, eds. Hans-Georg Gadamer on education, poetry and history. New York: State University of New York Press, 1992, 63-71 at 70.

6 Weedon C. Feminist practice and poststructural theory. Cambridge: Blackwell, 1987.

7 Sandywell B. Specular grammar: the visual rhetoric of modernity. In: Heywood I, Sandywell B, eds. Interpreting visual culture: explorations in the hermeneutics of the visual. London: Routledge, 1999:30-5.

8 Smith D. Writing the social. Toronto: University of Toronto Press, 1999.

9 Lyotard JF. The postmodern condition: a report on knowledge [trans Bennington G, Massumi B]. Manchester: Manchester University Press, 1979.

10 Foucault M. Power/knowledge: selected interviews and other writings 19721977 [trans Bouchard D, Simon S]. New York: Pantheon Books, 1980.

11 Lacan J. Ecrits: a selection [trans Sheridan A]. London: Tavistock, 1977.

12 Carson T. Reflection and its resistances: teacher education as a living practice. In: Carson T, Sumara D, eds. Action research as a living practice. New York: Peter Lang, 1997:77-91.

13 Bruner J. Acts of meaning. Cambridge, MA: Harvard University Press, 1990.

14 Garro L, Mattingly C. Narrative as construct and construction. Narrative and the cultural construction of illness and healing. Berkeley: University of California Press, 2000: 1-49.

15 Nelson HL. Damaged identities: narrative repair. Ithaca, NY: Cornell University Press, 2001

16 Polkinghorne DE. Narrative knowing and the human sciences. New York: State University of New York Press, 1988:150.

17 Kearney R. Strangers, gods, and monsters: interpreting otherness. London: Routledge, 2003.

18 Ricoeur P. Oneself as another. Chicago: University of Chicago Press, 1992.

19 Bohm D. On dialogue. London: Routledge, 1996.

20 Nichol L. Foreword. In: Bohm D. On dialogue. London: Routledge, 1996, vii-xviii.

21 Taylor C. The ethics of authenticity. Cambridge, MA: Harvard University Press, 1992.

22 Kearney R. The wake of imagination. London: Routledge, 1988:387.

23 Bakhtin M. The dialogic imagination [trans Emerson C, Holquist M]. Austin, TX: University of Texas Press, 1981.

24 Bakhtin M. Art and answerability [trans Liapunov V, Brostrom K]. Austin, TX: University of Texas Press, 1990:194.

25 Bakhtin M. Toward a philosophy of the act. Austin, TX: University of Texas Press, 1993:3.

26 Bender C. Bakhtinian perspective on "everyday life" sociology. In: Bell M, Gardiner M, eds. Bakhtin and the human sciences. London: Sage, 1998;181195 at 190.

27 Taylor C, White S. Practising reflexivity in health and welfare: making knowledge. Buckingham: Open University Press, 2000.

28 Levinas E. Totality and infinity. Pittsburgh: Dusquesne University Press, 1969.

29 Gardiner M. Bakhtin and the metaphorics of perception. In: Heywood I, Sandywell B, eds. Interpreting visual culture: explorations in the hermeneutics of the visual. London: Routledge, 1999:64.

30 Bakhtin M. The Bakhtin reader. London: Edward Arnold, 1994.

31 Rich A. Arts of the possible. New York: W W Norton and Co, 2001

32 Lather P. Getting smart: feminist research and pedagogy with/in the postmodern. New York: Routledge, 1991.

33 Sandywell B. Reflexivity and the crisis of Western reason: logological investigations. London: Routledge, 1996:xvi.

34 Cixous H, Calle-Gruber M. Rootprints: memory and life writing [trans Prenowitz E]. New York: Routledge, 1997:178.

35 Foucault M. The archaeology of knowledge. London: Tavistock, 1974.

36 Hall S. Foucault: power, knowledge and discourse. In: Wetherell M, Taylor, S, Yates S, eds. Discourse theory and practice. London: Sage, 2001:72-81.

37 Gee JP. What is literacy? In: Mitchell C, Weiler K, eds. Rewriting literacy: culture and the discourse of the other. New York: Bergin \& Garvey, 1991.

38 Gee JP. An introduction to discourse analysis: theory and method. London: Routledge, 1999

39 Addelson KP. The man of professional wisdom. In: Harding S, Hintikka M, eds. Discovering reality. Boston: D Reidel, 1983:165-86.

40 Rich A. Invisibility in academe. In: Rosaldo R, eds. Culture and truth: the remaking of social analysis. Boston: Beacon Press, 1989.

41 Frye M. The politics of reality. Freedom, CA: Crossing, 1983.

42 Chapman V. On "knowing one's self" self writing, power and ethical practice: reflections from an adult educator. Studies in the Education of Adults 2003;35:35-53.

43 Wetherall M. Themes in discourse research. In: Wetherell M, Taylor S, Yates S, eds. Discourse theory and practice. London: Sage, 2001:14-28.

44 Wendell S. The rejected body: feminist philosophical reflections on disability. New York: Routledge, 1996. 